\title{
Surgical anatomy of the breast revisited
}

\author{
Wojciech M. Wysocki² 2, 3, Guido Libondi ${ }^{3}$, Aleksiej Juszczak¹,3 \\ 'Department of Surgery, Faculty of Medicine and Health Sciences, Andrzej Frycz Modrzewski Krakow University, Krakow, Poland \\ ${ }^{2}$ Scientific Editors, Maria Sklodowska-Curie National Research Institute of Oncology, Warsaw, Poland \\ ${ }^{3}$ Clinic of General Oncological and Vascular Surgery, 5. Military Clinical Hospital with a Polyclinic, Krakow, Poland
}

With the advent of breast conservation options in the 1970s, as well as wider acceptance of breast reconstruction in cancer patients in 1980/1990, ending up with evolution of oncoplastic concepts in the early 2000s, detailed surgical anatomy of the breast became important. This short article reviews surgical anatomy of breast with particular emphasis on innervation and blood supply to the skin and nipple-areolar complex, as well as points out the concept of compartmental breast cancer anatomy. Meticulous dissection and avoidance of transection of major vessels and nerves constitutes the crucial factor for satisfactory results of surgery in terms of preservation of sensation as well as appropriate vitality of skin.

NOWOTWORY J Oncol 2020; 70, 1: 26-28

Key words: breast, surgery, anatomy, blood supply, innervation

\section{Introduction}

Definition of breast in English language dictionary is straightforward - a gland located on the anterior wall of female's thorax [1]. Detailed anatomy of the breast was for many years regarded as of marginal importance for surgical oncologists (apart from axilla anatomy). This could be mainly attributed to the fact that since Halsted's innovative concept in the end of $19^{\text {th }}$ century, the breast surgery in cancer patients was only ablative and radical - the standard treatment was a radical mastectomy [2].

With the advent of breast conservation options in the 1970s [3-5], as well as wider acceptance of breast reconstruction in cancer patients in 1980/1990, ending up with evolution of oncoplastic concepts in the early 2000s, detailed surgical anatomy of the breast became important. Special attention was paid to the innervation of skin covering the gland (and to the innervation of nipple-areolar concept) and to the blood supply of the breast skin and - mainly - nipple/areola complex.

This short article reviews surgical anatomy of breast with emphasis on innervation and blood supply to the skin and nipple-areolar complex, as well as points out new concept of compartmental breast cancer surgery.

\section{Breast blood supply}

Breast blood supply comes from three main sources:

1. Internal mammary (aka thoracic) artery (IMA/ITA), which is a branch of subclavian artery; it supplies mainly the medial portion of the breast (by its anterior and posterior perforating branches). Internal mammary artery delivers about $60 \%$ of total breast blood flow.

2. Lateral thoracic artery (LTA), which arises from axillary artery or thoracoacromial artery or subscapular artery and supplies mainly the lateral and upper outer portions of the breast; lateral thoracic artery represents circa $30 \%$ of total blood flow in healthy female.

3. The remaining breast blood flow is provided by the $\mathbf{2}^{\text {nd }}$ to $\mathbf{6}^{\text {th }}$ intercostal artery perforators. The intercostal arteries arise directly from aorta; the $5^{\text {th }}$ and $6^{\text {th }}$ perforators serve as the blood supply of the inferior pole of the breast. The second to fourth internal mammary artery perforators exit intercostal spaces approximately $2 \mathrm{~cm}$ laterally to the sternum; these vessels at that anatomical area during surgical dissection should be preserved, if possible. Anterior branches continue to run within the subcutaneous tissue of the breast and are found usually 0.5 to $1 \mathrm{~cm}$ deeper, from the medial 
surface of the skin, reaching the nipple/ areola complex from the medial part. The importance of ITA branches for breast cancer surgery results from the following facts:

- these perforators are dominating blood suppliers to the breast ( $60 \%$ of total blood supply to the breast),

- higher blood filling pressure in these branches (close next),

- well-developed anatomoses between these vessels and neighbouring vessels.

That is why pedicled oncoplastic reconstructions based on these vessels is safe and effective. Moreover these perforators are used as an alternative recipient vessels in microsurgical breast reconstruction [6-10].

Lateral thoracic artery branches are frequently found from 1 to $2.5 \mathrm{~cm}$ from the skin surface (i.e. deeper compared to ITA branches), as more subcutaneous tissue is present in the lateral quadrants of the breast as opposed to its medial parts. That is why as the areola is approached, vessels climb more and more superficial. Peripheral branches of LTA course infero-medially within the subcutaneous tissue to finally anastomose with branches of the ITA/IMA and intercostal arteries in the NAC area [6-9].

A minor blood supply derives from the perforators of the pectoral branch of the thoracoacromial artery, a branch of the axillary artery.

Nipple-areola complex main blood supply is provided by branches of both ITA/IMA and LTA, which communicate with each other behind the areola. Small branches deriving from these communicating vessels run upward, toward nipple and surrounding areola. Minor vessels reach the base of the nipple and give off even finer vessels travelling to the areolar skin, and ascending into the nipple; vessels arborize in the upper and middle thirds of the nipple [6-9].

Moreover from the surgical point of view it is important to emphasize that the skin of the breast and the NAC are supplied by a continuous vascular plexus formed by the anastomoses of the aforementioned vessel; it is mainly a subdermal plexus running between the superficial fascia of the breast and the subcutaneous fat of the skin and its viability is mainly influenced by the surgical technique [11].

\section{Breast sensory innervation}

Sparing the nipple and areola during breast oncoplastic and reconstructive surgery serves virtually no purpose, if the nipple is insensate postoperatively.
Sensory innervation of the breast skin comes from lateral cutaneous branches of the $2^{\text {nd }}$ through $6^{\text {th }}$ intercostal nerves and anterior cutaneous branches of the $2^{\text {nd }}$ through $6^{\text {th }}$ intercostal nerves. Lateral branches of the intercostal nerves exit the intercostal spaces at the anterior attachment sites of serratus anterior muscle; afterwards these branches cross breast parenchyma (deep branches) and reach nipple-areolar complex from behind. Anterior branches of the intercostal nerves run superficially within subcutaneous tissue beneath the skin, do not cross breast parenchyma (this is opposite to the lateral branches, which crosses the parenchyma) and approach nipple-areolar complex from the medial aspect of areola.

It is important to underline, that $2^{\text {nd }}$ and $3^{\text {rd }}$ intercostal nerves give rise only to cutaneous branches to the very superior aspect of the breast. Additionally limited region over the upper portion of the breast supplied by the cervical plexus (i.e. anterior or medial branches of the supraclavicular nerve). Innervation of the remaining breast comes mainly from the $4^{\text {th }}, 5^{\text {th }}$ and $6^{\text {th }}$ intercostal nerves. All these nerves convey sympathetic fibers to the breast and overlying skin and influence: - flow of blood through vessels,

- secretory function of the sweat glands. Secretory function of the gland is regulated by hormonal axis [6-9].

Nipple innervation relies solely on branches of $4^{\text {th }}$ intercostal nerve: it is assessed that over $90 \%$ of innervation of the nipples comes from deep branches of lateral cutaneous nerve (arising from the $4^{\text {th }}$ intercostal nerve), and for circa $7 \%$ of nipple innervation superficial branches of lateral cutaneous nerve (arising from the $4^{\text {th }}$ intercostal nerve) are responsible. These nerves are best protected if surgical resection starts at the base of the breast and skin incisions at the medial edge of the areola are avoided $[6-9,12]$. Table I sums up the data on nipple-areola complex innervation.

Lateral branch of the $2^{\text {nd }}$ intercostal nerve is of special significance because it gives away fibres to a large nerve - intercostal brachial nerve. It has limited functional significance, but if injured, patient losses cutaneous sensation from the upper medial aspect of arm and axilla floor [6-9, 12].

\section{Compartmental breast concept}

Würinger et al. described concept of horizontal fibrous septum dividing the breast parenchyma into upper and lower portions. It contains major vessels and nerves climbing up to the NAC. It extends medially from the sternum to the lateral edge of

Table I. Nipple-areola complex innervation

\begin{tabular}{|ll}
\hline Lateral branches & Anterior branches \\
\hline usually transected during mastectomy & usually transected during mastectomy \\
\hline often partially transected during majority of WLE/LE & often transected in medial quadrants WLE/LE \\
\hline $\begin{array}{l}\text { by meticulous planning and dissection deep and or superficial fibres } \\
\text { of lateral branches should be preserved (mainly peripherally located } \\
\text { tumors)! }\end{array}$ & meticulous planning and dissection to avoid transection \\
\hline
\end{tabular}


pectoral minor muscle, curving upwards at the lateral and medial border, reaching the level of $2^{\text {nd }}$ rib. On its horizontal part at the thoracic wall it follows the $5^{\text {th }}$ rib. The horizontal (transverse) septum serves as suspensory scaffolding for the breast $[13,14]$. Recently vertical septum was described, running from the infra-mammary crease centrally to the NAC, joining the horizontal septum and dividing lower portion of the breast into two parts [15]. These transverse and vertical septa create altogether compartmental breast structure and are directly linked to the anatomy of the breast vessels and nerves pathways, therefore are important in breast surgery planning.

\section{Conclusions}

Detailed knowledge of breast skin innervation and blood supply is mandatory for surgical oncologists performing breast surgery - reconstructive and oncoplastic resections. Meticulous dissection and avoidance of transection of major vessels and nerves is crucial factor for satisfactory results of surgery in terms of preservation of sensation as well as appropriate vitality of skin.

\section{Conflict of interest: none declared}

\section{Wojciech M. Wysocki}

5. Military Clinical Hospital with a Polyclinic

Clinic of General Oncological and Vascular Surgery

ul. Wrocławska 1-3

30-901 Kraków, Poland

e-mail:wwysocki@mp.pl

Received: 29 Jan 2020

Accepted: 10 Feb 2020

The article is based on the lecture presented by senior author (Wojciech M. Wysocki) during First Congress of Central and Eastern European Breast Cancer Surgical Consortium (CEEBCSC) in Budapest (12-14 June 2019).

\section{References}

1. Meriam-Webster Dictionary. https://www.merriam-webster.com/.

2. Halsted WS. I. The Results of Operations for the Cure of Cancer of the Breast Performed at the Johns Hopkins Hospital from June, 1889, to January, 1894. Ann Surg. 1894; 20(5):497-555, doi: 10.1097/00000658189407000-00075, indexed in Pubmed: 17860107.

3. Fisher B, Redmond C, Fisher E, et al. Ten-Year Results of a Randomized Clinical Trial Comparing Radical Mastectomy and Total Mastectomy with or without Radiation. N Engl J Med. 1985; 312(11): 674-681, doi: 10.1056/nejm198503143121102.

4. Fisher B, Anderson S, Bryant J, et al. Twenty-year follow-up of a randomized trial comparing total mastectomy, lumpectomy, and lumpectomy plus irradiation for the treatment of invasive breast cancer. $\mathrm{N}$ Engl J Med. 2002; 347(16): 1233-1241, doi: 10.1056/NEJMoa022152, indexed in Pubmed: 12393820.

5. Veronesi U, Zucali R, Luini A. Local control and survival in early breast cancer: the Milan trial. Int J Radiat Oncol Biol Phys. 1986; 12(5): 717-720, doi: 10.1016/0360-3016(86)90027-1, indexed in Pubmed: 3519549.

6. Wamalwa AO, Stasch T, Nangole FW, et al. Surgical anatomy of reduction mammaplasty: a historical perspective and current concepts. S Afr J Surg. 2017; 55(1): 22-28, indexed in Pubmed: 28876554.

7. Schlenz I, Kuzbari R, Gruber $\mathrm{H}$, et al. The sensitivity of the nipple-areola complex: an anatomic study. Plast Reconstr Surg. 2000; 105(3): 905-909, doi: 10.1097/00006534-200003000-00012, indexed in Pubmed: 10724249.

8. O'Connell RL, Rusby JE. Anatomy relevant to conservative mastectomy. Gland Surg. 2015; 4(6): 476-483, doi: 10.3978/j.issn.2227-684X.2015.02.06, indexed in Pubmed: 26645002.

9. Bland KI, Copeland EM, Klimberg S. Comprehensive Management of Benign and Malignant Diseases (Fifth Edition). The Breast 2018: 20-36.e2.

10. Saour S, Libondi G, Ramakrishnan V. Microsurgical refinements with the use of internal mammary (IM) perforators as recipient vessels in transverse upper gracilis (TUG) autologous breast reconstruction. Gland Surg. 2017; 6(4): 375-379, doi: 10.21037/gs.2017.05.04, indexed in Pubmed: 28861378.

11. Robertson SA, Rusby JE, Cutress RI. Determinants of optimal mastectomy skin flap thickness. Br J Surg. 2014; 101(8): 899-911, doi: 10.1002/ bjs.9470, indexed in Pubmed: 24664617.

12. Mallucci P, Branford OA. Shapes, Proportions, and Variations in Breast Aesthetic Ideals: The Definition of Breast Beauty, Analysis, and Surgical Practice. Clin Plast Surg. 2015; 42(4): 451-464, doi: 10.1016/j. cps.2015.06.012, indexed in Pubmed: 26408436

13. Würinger $E$, Mader N, Posch E, et al. Nerve and vessel supplying ligamentous suspension of the mammary gland. Plast Reconstr Surg. 1998; 101(6): 1486-1493, doi: 10.1097/00006534-199805000-00009, indexed in Pubmed: 9583477.

14. Würinger E. Secondary reduction mammaplasty. Plast Reconstr Surg 2002; 109(2): 812-814, doi: 10.1097/00006534-200202000-00064, indexed in Pubmed: 11818875.

15. Awad MA, Sherif MM, Sadek EY, et al. A New Septum in the Female Breast. Arch Plast Surg. 2017; 44(2): 101-108, doi: 10.5999/ aps.2017.44.2.101, indexed in Pubmed: 28352598. 